\title{
Cigarette smoking, alcohol intoxication and major depressive episode in a representative population sample
}

\author{
J Hämäläinen, J Kaprio, E Isometsä, M Heikkinen, K Poikolainen, S Lindeman, H Aro
}

National Public Health Institute, Department of Mental Health and Alcohol Research, Mannerheimintie 166, 00300, Helsinki,

Finland

J Hämäläinen

J Kaprio

E Isometsä

M Heikkinen

K Poikolainen

$S$ Lindeman

H Aro

Department of Public Health and General

Practice, University of Oulu, Oulu, Finland

J Kaprio

Department of Psychiatry, University of Oulu

$\mathrm{S}$ Lindeman

Finnish Foundation for Alcohol Studies, Finland

K Poikolainen

Tampere School of Public Health, University of Tampere, Tampere, Finland $\mathrm{H}$ Aro

Correspondence to: Dr Hämäläinen

(Juha.Hamalainen@ktl.fi)

Accepted for publication 5 April 2001

\begin{abstract}
Objective-This study investigated the associations of cigarette smoking and alcohol intoxication with major depressive episode.

Design-Major depressive episode during the past 12 months was assessed in a national representative cross sectional study using the Short Form of the University of Michigan version of the Composite International Diagnostic Interview (the UM-CIDI Short Form).

Subjects-A random sample of 5993 noninstitutionalised Finnish people aged 15-75 years was interviewed as a part of the 1996 Finnish Health Care Survey. Results-In logistic regression models the factors associated with major depressive episode in the past 12 months were smoking 10 or more cigarettes daily (odds ratio (OR) $2.26 ; 95 \%$ confidence intervals $(95 \%$ CI) $1.68,3.04$ ) and alcohol intoxication at least once a week (OR 2.99; 95\%CI 1.70, 5.25). Their effects were independent of each other, and remained significant even after adjusting for other major risk factors (marital status, education, unemployment and chronic diseases). The attributable proportion (a measure of the impact of the risk factors of the disease on the population) for daily smoking of 10 or more cigarettes was 0.15 , and for alcohol intoxication at least once a week 0.04 . Conclusion-Cigarette smoking and alcohol intoxication seem to be important risk factors for major depressive episode. In this population the impact of smoking was greater.
\end{abstract}

(F Epidemiol Community Health 2001;55:573-576)

Recent epidemiological studies have reported an association between smoking and major depression. ${ }^{1-4}$ This confirms earlier findings from clinical samples ${ }^{5}$ and studies linking smoking to depressive symptoms, ${ }^{7-9}$ although some exceptions have been noted. ${ }^{10}$ However, the extent to which smoking initiation precedes the onset of depression, and vice versa, remains to be fully resolved. ${ }^{11}$

The comorbidity between depression and alcoholism has been well documented: there is approximately 1.5 -fold to 2.0 -fold risk of depression among alcoholics compared with non-alcoholics in major community-based epidemiological surveys. ${ }^{12}$ In addition, this comorbidity is more common in women than men and order of onset also seems to be gender related: the multisite Epidemiological Catchment Area Study showed that alcoholism preceded the onset of major depressive episode in the majority of male cases $(78 \%)$, while in women depression was usually antecedent ( $66 \%$ of cases). ${ }^{13}$

Although cigarette smoking and alcohol consumption may both start with the desire to change moods positively, dysfunctional long term mental health consequences are probable. ${ }^{14}$ Alcohol consumption and alcoholism are strongly associated with cigarette smoking. ${ }^{15-17}$ Little is known of the overall relation between smoking, alcohol consumption and major depression. In a recent study ${ }^{18}$ the association between cigarette smoking and major depression persisted after both alcoholism and anxiety disorders were controlled for. Within the Finnish Health Care Survey we investigated the prevalence of DSM-III-R major depressive episode in the previous 12 months, finding it to be $9.3 \%$ (men $7.2 \%$, women $10.9 \%) .{ }^{19}$ We also found frequency of smoking and alcohol intoxication to be individually important risk factors for major depressive episode. ${ }^{19}$ The purpose of this study was to define which levels of smoking and alcohol use associate with major depressive episode, and if the effects of alcohol use and smoking on risk of depression are independent of each other, and of other risk factors.

\section{Methods}

This study forms part of a recent nationwide Finnish Health Care Survey (FHCS).$^{20}$ The basic target population comprised all resident household dwellers of Finland in 1996. Institutionalised persons (about 63 000) were excluded, leaving a final target population of some 5 million people. The sampling design was one stage cluster sampling in which households formed the clusters. The households were constructed by first drawing a random sample of index persons from the population register. The members of the household of each index person were identified from the population register via the address. All household members aged 15 and over were interviewed personally between 5 April and 21 June by professional interviewers employed by Statistics Finland and trained in the use of the UM-CIDI Short Form (see below).

The data were collected by the Computer Assisted Personal Interview (CAPI) technique. ${ }^{19}$ To assess depression, 24 structured items from the Short Form of the UM-CIDI were used to generate a probability diagnosis of 
DSM-III-R major depressive episode during the past 12 month period. The interview including the UM-CIDI Short Form items was given to persons aged $15-75$ years-that is, born 1921-1981. The overall household participation rate of completed interviews was $86 \%$ (3614 of 4200 households). ${ }^{20}$ The participating households yielded interview data on 6962 adults, for which proxy interviews were done on 959 subjects (13.8\%). As proxy information was not sought concerning the people with depression, and 10 further cases were excluded because of missing UM-CIDI items, the sample for analysis consisted of 5993 persons (2646 men, 3347 women), of whom 557 were depressed ( 367 women, $190 \mathrm{men}$ ). ${ }^{19}$

Questions on tobacco use covered current and earlier smoking status (five categories: lifetime non-smokers, former smokers, irregular smokers, 1-9 cigarettes smoked daily, and 10 or more smoked daily), the amount of tobacco products used daily and the duration of smoking in years. Questions on alcohol covered the frequency of consumption (five categories: daily or almost daily, once per week, two to three times per month, once per month or more infrequently and never) and the frequency of alcohol intoxication (four categories: once per week or more often, two to three times per month, once per month or more infrequently and never). The complete classification and distribution of other potential confounding factors studied (sex, age, employment, duration of education, marital status, residential area, body mass index, annual income of household, and any chronic medical conditions) are reported in the FHCS prevalence study. ${ }^{19}$

STATISTICAL ANALYSES

In the logistic regression analyses generalised estimating equations ${ }^{21}$ were used in the PROC GENMOD, SAS version 6.12, to account for the household sampling of the subjects. The attributable proportion (APT), a measure of the impact of the risk factors for the disease on the population, ${ }^{22}$ was also calculated for the exposed population.

Results

The proportion of daily smokers in the adult population was $19.5 \%,(26.1 \%$ men and $15.7 \%$ women). Alcohol was drunk daily or nearly daily by $9.2 \%$ of adults: $14.5 \%$ of men

Table 1 Sex and age adjusted odds ratios for the presence of major depressive episode by cigarette smoking and alcohol intoxication

\begin{tabular}{|c|c|c|c|}
\hline & $\begin{array}{l}\text { OR }(95 \% C I) \\
\text { both sexes }\end{array}$ & $\begin{array}{l}\text { OR }(95 \% C I) \\
\text { men }\end{array}$ & $\begin{array}{l}\text { OR }(95 \% C I) \\
\text { women }\end{array}$ \\
\hline \multicolumn{4}{|l|}{ Smoking status } \\
\hline Never & 1.00 & 1.00 & 1.00 \\
\hline Former & $1.47(1.15,1.87)$ & $1.44(0.95,2.18)$ & $1.52(1.12,2.06)$ \\
\hline Irregular & $1.70(1.09,2.67)$ & $0.92(0.36,2.36)$ & $2.22(1.32,3.73)$ \\
\hline 1-9 cigarettes per day & $1.71(1.14,2.56)$ & $2.19(1.14,4.22)$ & $1.49(0.89,2.51)$ \\
\hline $\begin{array}{l}\geqslant 10 \text { cigarettes per day } \\
\text { Alcohol intoxication }\end{array}$ & $2.55(2.03,3.20)$ & $2.49(1.72,3.60)$ & $2.59(1.92,3.47)$ \\
\hline Abstainer & 1.00 & 1.00 & 1.00 \\
\hline Never & $0.98(0.76,1.28)$ & $0.67(0.40,1.13)$ & $1.11(0.82,1.51)$ \\
\hline$<1$ time/month & $1.30(0.99,1.72)$ & $0.95(0.59,1.53)$ & $1.47(1.05,2.07)$ \\
\hline $2-3$ times/month & $1.76(1.11,2.80)$ & $1.44(0.78,2.66)$ & $1.56(1.05,2.07)$ \\
\hline$\geqslant 1$ time/week & $4.54(2.73,7.55)$ & $2.61(1.32,5.15)$ & $11.15(4.34,28.60)$ \\
\hline
\end{tabular}

KEY POINTS

- In a representative population sample cigarette smoking seems to be an important risk factor for major depressive episode; the risk increases with number of cigarettes smoked daily and years smoked.

- Alcohol intoxication seems also to be an important risk factor for major depressive episode; the risk increases with frequency of intoxication.

- Both cigarette smoking and alcohol intoxication are associated with major depressive episode independently of each other.

and $5.0 \%$ of women. Alcohol consumption frequency was systematically associated with income, men and women in the highest quintile being regular drinkers more often than those in the other quintiles. The rate of alcohol intoxication at least once a week was $2.2 \%$, being commoner among men (4.0\%) than women $(0.1 \%)$. Weekly intoxication was most common in the 35-54 years age group. People in the lowest income quintile had the highest intoxication rates.

Current smoking was a significant risk factor for major depressive episode compared with never smokers: the OR for current smoking was $2.24(95 \%$ CI $1.74,2.90)$. The former and irregular smokers had an increased but smaller risk. The OR for daily cigarette consumption as a continuous variable was 1.04 (95\% CI 1.02 , $1.06)$ and for 10 smoking years 1.02 (95\% CI $1.01,1.04)$. As for alcohol, only daily use compared with abstainers carried a higher risk of major depressive episode, although the risk increased with the frequency of drinking to intoxication (table 1).

In the logistic regression model, after controlling for other confounding factors (age, sex, marital status, education, household income, employment status, living area, body mass index, and (presence and number of chronic somatic medical conditions), the factors associated with major depressive episode were smoking 10 or more cigarettes per day (OR 2.26, 95\%CI 1.68, 3.04) and alcohol intoxication once weekly or more often (OR $2.99,95 \%$ CI 1.70, 5.25). Other significant risk factors in the model were current unemployment (OR 1.78, 95\% CI 1.38, 2.29), disability pension (OR 2.34, 95\%CI 1.62, 3.38), one or two chronic diseases (OR 1.47, 95\% CI 1.18,

Table 2 Odds ratios for the presence of major depressive episode by selected demographic and lifestyle characteristics, logistic regression model

\begin{tabular}{ll}
\hline Characteristics & OR $(95 \%$ CI $)$ \\
\hline Smoking $\geqslant 20$ cigarettes per day & $1.85(1.33,2.58)$ \\
Smoking $\geqslant 10$ cigarettes per day & $2.26(1.68,3.04)$ \\
Alcohol intoxication $\geqslant 1$ time/week & $2.99(1.70,5.25)$ \\
Age & $1.00(0.99,1.01)$ \\
Sex, female & $2.09(1.71,2.55)$ \\
Disability pension & $2.34(1.62,3.38)$ \\
Unemployed & $1.78(1.38,2.29)$ \\
Chronic medical conditions $1-2$ & $1.47(1.18,1.82)$ \\
Chronic medical conditions $>2$ & $2.49(1.85,3.34)$ \\
\hline
\end{tabular}


1.82), and three or more chronic diseases ( $O R$ $2.49,95 \% \mathrm{CI} 1.85,3.34)$. We found no evidence for interaction effects between alcohol and smoking in the logistic regression analyses (table 2).

On the population level daily tobacco use (over 10 cigarettes/day) in this model was a very important contributor to major depressive episode $(\mathrm{APT}=0.11)$, although less so than having three or more chronic conditions (APT $=0.16)$. Alcohol intoxication had a smaller impact on the population level $(\mathrm{APT}=0.03)$ because its prevalence is low despite a higher relative risk.

\section{Discussion}

We found that alcohol intoxication at least once per week and smoking 10 or more cigarettes daily is associated with the risk of major depressive episode. This study also reports that at the population level both cigarette smoking and alcohol intoxication, after adjusting for other risk factors, are associated with major depressive episode independently of each other.

This study involved a large random sample of a non-institutionalised general population $(n=5993)$ representing the whole of Finland. The participation rate of households interviewed was high and the interviews were made by professional interviewers specially trained by two experienced psychiatrists in the use of the UM-CIDI Short Form. The study sample is closely comparable to the entire Finnish population for the sociodemographic characteristics investigated. ${ }^{19}$ The Short Form of the UM-CIDI is a shortened form plus an algorithm based on the NCS findings. The characteristics of this method are discussed in the FHCS prevalence study. ${ }^{19}$ No indication of cultural biases in the validity of UM-CIDI has arisen. Our prevalence estimate for major depressive episode was convergent with most other general population studies. ${ }^{19}$ Our instrument did not generate diagnoses of specific mood disorders but only of major depressive episode. It is probable that most of the people with a major depressive episode had unipolar major depression. For comparison, in the Epidemiological Catchment Area (ECA) study ${ }^{23}$ $77 \%$ of subjects with major depressive episode had unipolar major depression and most of the remainder were suffering from bipolar disorders or bereavement. We also lacked diagnostic level information on substance abuse or dependence. In earlier studies with adults, the association between smoking and $\mathrm{MDD}^{24}$ and (mild or moderate) nicotine dependence and MDD, ${ }^{25}$ remained significant even after controlling for other psychiatric disorders.

These cross sectional data can only suggest, not prove, causal relations. The strong association of cigarette smoking with major depression indicates that smoking may be an important risk factor both on the individual and population level. It has been suggested that causes of major depression may include both genetic and enviromental factors. ${ }^{24}$ There may be separate specific causal mechanisms from smoking to major depression, and vice versa. It is also possible that smoking may be a marker of a variety of genetic, personal, social and familial properties. ${ }^{26}$ Thus, resolution of causality even in longitudinal studies is not a simple issue.

However nicotine, the pharmacologically active component of cigarette smoke, is known to have direct and indirect effects on the neurotransmitters thought to be involved in major depression. ${ }^{27}$ There is speculation of a specific relation between smoking and major depression only in smokers who are nicotine dependent. ${ }^{26}$ This hypothesis is suggested by findings ${ }^{2}$ indicating that increased rates of major depression are found only among nicotine dependent smokers and not nondependent smokers. Our findings suggest a relation between the prevalence of major depressive episode and the consumption of cigarettes: current smoking over 10 cigarettes per day was significantly associated with major depressive episode. The increased association for those smoking under 10 cigarettes per day or for irregular smokers was less consistent. Among former smokers, the prevalence of major depression was increased only in women.

The increased incidence of alcoholism among smokers ${ }^{16}$ may be partially responsible for the relation observed between smoking and depression, although some such findings have been independent of alcohol intake. ${ }^{1-3}$ Factors such as education may also exert a role-lower educational attainment is often associated with a greater prevalence of smoking ${ }^{28} 29$ and has been implicated in failure to stop. ${ }^{28}{ }^{30}$ Other suggested confounding factors between smoking and depression include age, ${ }^{31}$ obesity, ${ }^{32}$ and sex, with many studies showing a stronger relation between smoking and depressive symptoms among women. ${ }^{43-35}$ In our model the other possible confounding factors were adjusted for one by one, after which only frequent alcohol intoxication (weekly or more often) and sex remained statistically significant in the final model. Neither educational attainment, obesity nor age had a statistically significant effect.

Most studies investigating the comorbidity between major depression and alcoholism have focused on diagnostic level information ${ }^{36}{ }^{37}$; few have assessed the nature of relations between depressive symptoms and problematic alcohol use. $^{38}$

In conclusion, both cigarette smoking and alcohol intoxication seem to be important risk factors for major depressive episode. In our population the impact of smoking was greater.

Funding: the study was financially supported by the Yrjö Jahnsson Foundation and the Academy of Finland (grant number 42044).

Conflicts of interest: none.

1 Glassman AH, Helzer JE, Covey LS, et al. Smoking, smoking cessation, and major depression. $7 A M A$ 1990;264:1546-9.

2 Breslau N, Kilbey MM, Andreski P. Nicotine dependence, major depression, and anxiety in young adults. Arch Gen Psychiatry 1991;48:1069-74.

3 Kendler KS, Neale MC, MacLean CJ, et al. Smoking and major depression: a causal analysis. Arch Gen Psychiatry 1993;50:36-43.

4 Isometsä E, Aro S, Aro H. Depression in Finland: a computer assisted telephone interview study. Acta Psychiatr Scand 1997;96:122-8. 
5 Hughes JR, Hatsukami DK, Mitchell JE, et al. Prevalence of smoking among psychiatric outpatients. Am f Psychiatry 1986;14:9

6 Glassman AH, Stetner F, Walsh T, et al. Heavy smokers, smoking cessation, and clonidine. $\mathcal{F} A M A$ 1988;259:2863-6.

7 Kandel DB, Davies M. Adult sequelae of adolescent depressive symptoms. Arch Gen Psychiatry 1986;43:255-62.

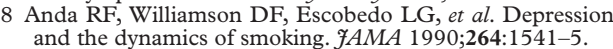

Patton GC, Hibbert M, Rosier MJ, et al. Is smoking associated with depression and anxiety in teenagers? Am f Public Health 1996; 86:225-30.

10 Covey LS, Hughes DC, Glassman AH, et al. Ever-smoking, quitting, and psychiatric disorders: evidence from the Durham, North Carolina, Epidemiologic Catchment Area. Tobacco Control 1994;3:222-7.

11 Glassman AH, Stetner F, Walsh BT, et al. Heavy smokers, smoking cessation, and clonidine. Results of a doubleblind, randomized trial. $¥ A M A$ 1988;259:2863-6.

12 Merikangas K, Gelernter C. Comorbidity for alcoholism and depresssion. Psychiatr Clin North Am 1990;13:613-32.

13 Helzer JE, Przybeck T. The co-occurence of alcoholism with Helzer JE, Przybeck T. The co-occurence of alcoholism with
other psychiatric disorders in the general population and its other psychiatric disorders in the general population and
impact on treatment. $\mathcal{F}$ Stud Alcohol 1988;49:219-24.

14 Aneshensel C, Huba G. Depression, alcohol use, and smoking over one year: a four-wave longitudinal causal model. $\mathcal{F}$ Abnorm Psychol 1983;92:134-50.

15 Covey LS, Glassman AH, Stetner F, et al. Effect of history of alcoholism or major depression on smoking cessation. Am F Psychiatry 1993;150:1546-7.

16 DiFranza JK, Guerrera MP. Alcoholism and smoking. $\mathcal{F}$ Stud Alcohol 1990;51:130-5.

17 Glassman AH. Blue mood, blackened lungs:depression and smoking. FAMA 1990;264:1583-4.

18 Glassman AH, Covey LS, Dalack GW, et al. Smoking cessation, clonidine, and vulnerability to nicotine among

19 Lindeman S, Hämäläinen J, Isometsä E, et al. The 12-month prevalence and risk factors for major depressive episode in prevalence and risk factors for major depressive episode in atr Scand 2000;102:178-84.

20 Arinen S, Häkkinen U, Klaukka T, et al. Health and use of health services in Finland. Main findings of the Finnish Health Care Survey and changes from 1987. [In Finnish, English summary). Helsinki: Official Statistics of Finland, 1998.

21 Liang KY, Zeger SL. Longitudinal data analysis using generalized linear models. Biometrika 1986;73:13-22.

22 Rothman KJ. Modern epidemiology. Boston: Little, Brown, 1989.

23 Weissman MM, Bruce M, Leaf P, et al. Affective disorders. In: Robins L, Regier D, eds. Psychiatric disorders in America. New York: Free Press 1991:53-80.
24 Kendler KS, Neale MC, MacLean CJ, et al. Smoking and major depression. A causal analysis. Arch Gen Psychiatry 1993;50:36-43.

25 Breslau N, Kilbey M, Andreski P. Nicotine dependence, major depression, and anxiety in young adults. Arch Gen Psychiatry 1991;48:1069-74.

26 Breslau N, Peterson EL, Schultz LR, et al. Major depression and stages of smoking. Arch Gen Psychiatry 1998;55:161-6.

27 Hall SM, Munoz RF, Reus VI, et al. Nicotine, negative affect, and depression. F Consult Clin Psychol 1993;61:7617.

28 Pierce JP, Fiore MC, Novotny TE, et al. Trends in cigarette smoking in the United States: educational differences are increasing. $7 A M A$ 1989;261:56-60.

29 Wagenknecht LE, Perkins LL, Cutter GR, et al. Cigarette smoking behaviour is strongly related to educational status: the CARDIA study. Prev Med 1990;19:158-69.

30 Hatziandreu EJ, Pierce JP, Lefkopoulou M, et al. Quitting smoking in the United States in 1986. I Natl Cancer Inst 1990;82:1402-6.

31 Maier W, Lichtermann D, Oehrlein A, et al. Depression in the community: a comparison of treated and non-treated cases in two non-referred samples. Psychopharmacology 1992;106 (suppl):79-81.

32 Istvan J, Zavela K, Weidner G. Body weight and psychological distress in NHANES I. Int $\mathcal{F}$ Obes Relat Metab Disord 1992;16:999-1003.

33 Frederick T, Frerichs RR, Clark VA. Personal health habits and symptoms of depression at the community level. Prev Med 1988;17:173-82.

34 Peres-Stable EJ, Marin G, Marin BV, et al. Depressive symptoms and cigarette smoking among Latinos in San Francisco. Am f Public Health 1990;80:1500-2.

35 Lee DJ, Markides KS. Health behaviours, risk factors, and health indicators associated with cigarette use in Mexican Americans: results from the Hispanic HANES. Am 7 Public Health 1991;81:859-64.

36 Bromet EJ, Parkinson DK, Curtis EC, et al. Epidemiology of depression and alcohol abuse/dependence in a managerial and professional work force. F Occup Med 1990;32:989-95.

37 Kessler RC, Mc Gonagle KA, Zhao S, et al. Lifetime and 12 -month prevalence of DSM-III-R psychiatric disorders in the United States: a result from the National Comorbidity Survey. Arch Gen Psychiatry 1994;51:8-18.

38 Moscato BS, Russell M, Zielezny M, et al. Gender differences in the relation between depressive symptoms and alcohol problems: a longitudinal perspective. Am $\mathcal{F}$ Epimediol 1997;11:966-74. 